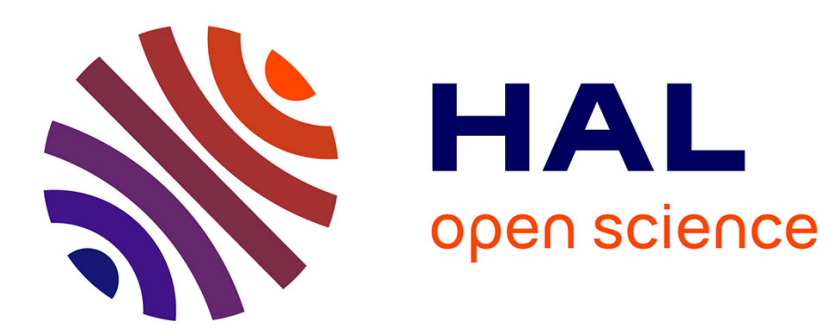

\title{
Plasmas in liquids and some of their applications in nanoscience
}

\author{
W G Graham, K R Stalder
}

\section{To cite this version:}

W G Graham, K R Stalder. Plasmas in liquids and some of their applications in nanoscience. Journal of Physics D: Applied Physics, 2011, 44 (17), pp.174037. 10.1088/0022-3727/44/17/174037 . hal00613289

\section{HAL Id: hal-00613289 \\ https://hal.science/hal-00613289}

Submitted on 4 Aug 2011

HAL is a multi-disciplinary open access archive for the deposit and dissemination of scientific research documents, whether they are published or not. The documents may come from teaching and research institutions in France or abroad, or from public or private research centers.
L'archive ouverte pluridisciplinaire HAL, est destinée au dépôt et à la diffusion de documents scientifiques de niveau recherche, publiés ou non, émanant des établissements d'enseignement et de recherche français ou étrangers, des laboratoires publics ou privés. 


\title{
Plasmas in Liquids and some of their Applications in Nanoscience.
}

\author{
W G Graham and K R Stalder \\ Centre for Plasma Physics \\ School of Mathematics and Physics \\ Queen's University Belfast \\ Belfast BT7 1NN \\ United Kingdom
}

Email: b.graham@qub.ac.uk, krstalder@staldertechnologies.com

\begin{abstract}
The range of applications for plasmas in liquids, plasmas in contact with liquid surfaces and plasmas containing liquid drops is growing rapidly across a range of technologies. Here the focus is on plasmas where the electrodes are immersed in liquids and their applications in nanoscience. The physical phenomena in both high voltage $(\sim 10$ 's $\mathrm{kV}$ ) and low voltage (few hundred V) plasmas in liquid are described together with a discussion of the plasma induced chemistry. Studies show that in water the plasmas are formed in water vapour created by Joule heating as either channels in the liquid or as layers on the electrodes. The chemistry in these water vapour plasmas and at their interface with the liquid is discussed in the context of the highly reactive radicals produced, such as $\mathrm{H}$ and $\mathrm{OH}$. The current use of a variety of plasmas-in-liquid systems in the area of nanoscience is discussed, with an emphasis on nanoparticle growth.
\end{abstract}

PACS: 52.77.Fv, 52.50.-b, 52.80.Wq, 64.70.F- , 81.07.-b

\section{Introduction}

Plasmas produced by electrical discharges in liquids are finding wide applicability in a number of modern technology areas. Whereas conventional gas discharges operate in environments where the electrodes and insulating structures are fixed and operate with gas pressures typically at or below one atmosphere, discharges in liquids have the added complexity that the liquid can vaporize-which leads to discontinuous liquid-vapour boundaries-and the liquid-vapour boundary is not fixed so that the discharges can exhibit much more complex hydrodynamic behaviour. Moreover, these discharges typically operate at or above atmospheric pressure, so the vapour densities are usually quite high compared to low-pressure discharges; consequently these discharge regimes provide a plethora of chemical reactions whose unique products can be exploited for the intended application. Many of the experiments on plasmas in liquids produce strongly non-equilibrium plasmas, where the electron temperatures are much larger than the vapour temperature and the liquid temperature. Earlier reviews of research on non-equilibrium plasmas in liquids have been compiled, for example, by Yerokhin et al. 1999, Malik et al. 2001, Locke et al. 2006 and more recently by Bruggemann and Leys 2009a. Combinations of high density and strongly non-equilibrium plasma conditions can produce many interesting and technologically-useful chemically-active environments. For example, high-voltage discharges in low-conductivity water produce short-lived gas-phase and liquid-phase transient species such as hydroxyl $(\mathrm{OH})$ and atomic hydrogen $(\mathrm{H})$ radicals, as well as more stable chemical species such as hydrogen peroxide $\left(\mathrm{H}_{2} \mathrm{O}_{2}\right)$ and ozone $\left(\mathrm{O}_{3}\right)$; all of these species are chemically active and can be used to cleanse the water of unwanted pollutants.

In this review we restrict ourselves to plasmas formed by electrical discharges employing 
electrodes immersed in the liquid. Broadly speaking, and for the purposes of this review, we separate discharge regimes into two main classes: those at kilovolt or higher voltages in relatively low conductivity liquids and those below kilovolt voltages in relatively high conductivity liquids. Applications in the high-voltage regime include pollution remediation [e.g. Lukes et al. 2004, Sunka et al. 2004, Kirkpatrick and Locke 2006, Yan et al. 2008], dielectric insulation [e.g Jones and Kunhardt 1994], pulse-power applications and switches [e.g. Martin et al.] and sources of UV radiation [e.g. Robinson et al. 1973]. These high voltage discharges produce some features also seen in gaseous discharges, such as streamers and strong acoustic effects [e.g. Devins and Rzad 1982, Chadband 1988, Beroual et al. 1988, Massala et al. 1998, Touya et al. 2006, An et al. 2007, Kolb et al. 2008, Ceccato et al. 2010] Applications in the low-voltage regime include some plasma-based electrosurgery [e.g. Stalder et al. 2001, Woloszko et al. 2002, Stalder et al 2005, Stalder and Woloszko 2007], sterilization [e.g. Sakiyama et al. 2009], glow discharge electrolysis for a variety of applications [e.g. Sengupta et al. 1997, Sengupta et al. 1998, Kobayashi et al. 2000, Gao et al. 2001, Gao et al. 2003a, Gao et al. 2003b, Gao et al. 2004, Mizuno et al. 2005, Gao et al. 2006, Yan et al. 2006, Liu and Jiang 2008, Wang et al. 2008, Wang 2009], and deposition of nanocrystalline films [e.g. Paulmier et al. 2007a, Paulmier et al. 2007b]. Recent basic studies of low-voltage discharges include those by Schaper et al. 2010a and Schaper et al. 2010b. A noteworthy feature of many of the low-voltage discharges in highly conducting liquids is an approximately linear (ohmic) current-voltage behaviour at low-voltage which transitions to a higher resistance regime as the voltage is increased, thus indicative of the formation of a lowconductivity vapour layer over the electrode. As the voltage is increased further the resistance decreases due to the initiation of electrical discharges in the vapour layer and subsequent formation of an ionized plasma in the vapour layer.

Some experiments have been conducted in hybrid regimes that don't fit easily into our discharge classification scheme, that is, for example, high-voltage discharges in high-conductivity water [Boguslavsky et al. 2001, Skibenko et al. 2006] and high-voltage DC discharges in lowconductivity water [Bruggeman et al. 2009b] and high-voltage AC capillary discharges in lowconductivity water [De Baerdemaeker et al. 2007] . It should also be noted that plasmas may be formed in liquid by other means, including laser heating [e.g. Vogel et al. 1996, Nahen and Vogel 1996], and even through focused sound waves [e.g. Flannigan and Suslick 2005]. In addition, there have been numerous studies of plasmas formed externally to liquids and made to interact with them [e.g. Janca et al. 1999, Baba et al. 2006, Kitano et al. 2006, Sugama et al. 2006, Richmonds and Sankaran 2008, Shirai et al. 2009, Chang et al. 2010, Chiang et al. 2010].

In addition, by looking at voltage pulses with durations from tens of nanoseconds to dc, we restrict our discussion to situations where a liquid-vapour phase transition is involved in the discharge mechanism. We therefore exclude the recent work with ultrashort, intense voltage pulses, which intriguingly suggests direct ionization in the liquid phase (Starikovskiy et al 2010). Although discharges in liquids can be produced in a number of different types of liquids, water-and solutions derived from it-clearly has received the most attention, primarily because it is ubiquitous and it is one of the most versatile solvents. Since salts and other ionic compounds are easily dissolved in water, thus forming an electricallyconducting medium through ionic conduction, its conductivity can be tailored over a wide dynamic range, simply by adjusting the concentration of the salt. For example, the difference in ionic conductivity between ultrapure water and water with $1 \% \mathrm{NaCl}$ by weight dissolved in it is over 6 orders of magnitude. Water also has a fairly large temperature coefficient of electrical conductivity; the conductivity of $1 \% \mathrm{NaCl}$ nearly doubles from $10^{\circ} \mathrm{C}$ to $40^{\circ} \mathrm{C}$. Finally, as is well known, at atmospheric pressure water boils at approximately $100^{\circ} \mathrm{C}$, which is easily achieved in many electrical discharges in water. In a boiling process, the density of the water vapour decreases by nearly 3 orders of magnitude from that of the liquid. 
Since this topical review is in the area of nanoscience there will be an emphasis on nanoparticles which can be produced or treated in plasmas produced by electrical discharges in liquids. We note that nanoparticles may also be produced in plasmas produced externally of the liquid but impinging on the liquid [e.g. Richmonds and Sankaran 2008, Chang et al. 2010, Chiang et al. 2010], and in spark discharges in liquid-free environments [e.g. Messing et al. 2009].

\section{Physics}

The study of the physics phenomena in the initiation, maintenance and termination of plasmas or discharges created in liquids is very challenging involving plasma physics, thermodynamics, hydrodynamics, cavitation and interactions at the gas - plasma -electrode - liquid interfaces. As mentioned above, the discussion is confined to a description of the underlying phenomena associated with two diverse systems which both have potential use in the nanosciences. These are the high-voltage $(\sim 10$ 's $\mathrm{kV})$, large-gap breakdown in water and the relatively low-voltage breakdown (few hundred volts) in a higher conductivity, saline solution.

\subsection{High voltage breakdown in water}

In recent reports by Ceccato and co-workers [Ceccato 2009a, Ceccato et al. 2009, Ceccato et al. 2010] there are excellent summaries of the temporal development of a high voltage, large gap plasmas in water from a positively biased pin to a grounded plane electrode in water based on their measurements which enhance but are largely consistent those of others [Beroual et al. 1988, Beroual 1993, Lesaint and Gournay 1994, Fofana and Beroual 1998, Massala and Lesaint 1998, Vasily et al. 2007]. The spatially and temporally resolved evolution of the system is recorded by imaging of the light emission from the plasma and the refraction of backlighting light using shadowgraphy. The latter allowing the density variation of the water and hence vapour production to be observed. In the results from that publication, reproduced here, the peak applied voltage was between 30 and $40 \mathrm{kV}$, the gap was $40 \mathrm{~mm}$ and the water conductivity was between 7 and 50 $\mu \mathrm{S} / \mathrm{cm}$.

The typical discharge current behaviour, shown in figure 2.1, indicates that the electrical breakdown process can be described in terms of four phases or modes.

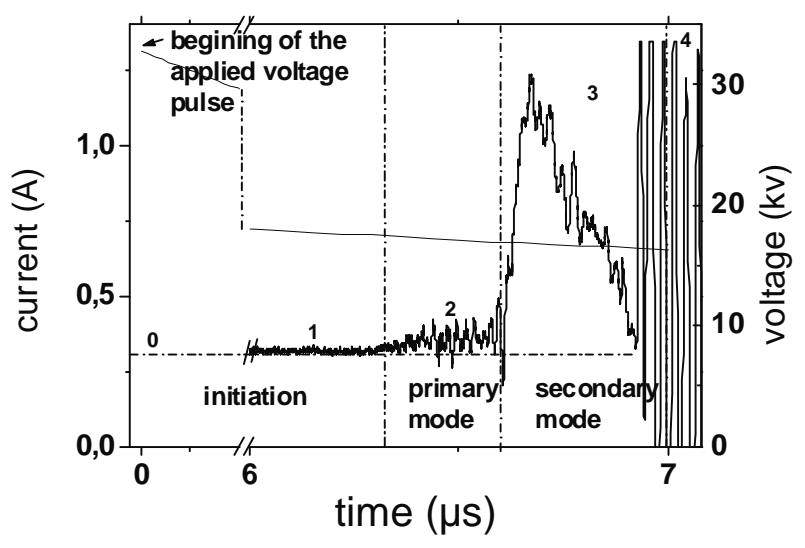

Figure 2.1. A typical current and voltage waveform in a pin to plane configuration in water (from Ceccato et al 2010) 
The initial current is initially almost constant, at a few hundred $\mathrm{mA}$, producing Joule heating of the liquid. Shadowgraphs reveal a micro-bubble growing on the metal surface of the tip of the electrode to some tens of microns in diameter (Figure 2.2). The length of this initiation phase-Region 1 in Figure 2.1-before the first light emission is observed, is not reproducible from shot to shot but is typically a few microseconds.

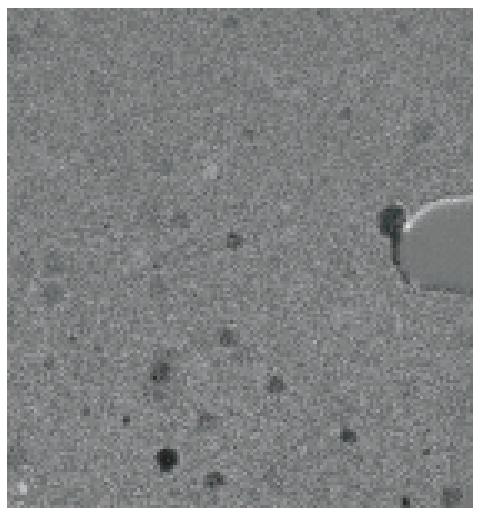

Figure 2.2. A typical shadowgraph taken in the pre-plasma phase showing the formation of a microbubble. The tip is $400 \mu \mathrm{m}$ in diameter [from Ceccato 2009b]

The discharge current then slowly rises (Region 2) and a luminous region forms and grows around the microbubble. This mode is difficult to resolve since it is composed of a series of weakly emitting, small filaments propagating less than a $\mathrm{mm}$ from the pin electrode to form bushlike filaments. This is the primary discharge mode (Figure $2.3 \mathrm{a}$ ). The emission intensity is higher at the tip of the primary filaments. This indicates that a high field region is concentrated in the filament tip and is responsible for the emission intensity. This is a well known phenomenon in gas-phase streamers where the propagation and the emission are entirely driven by a space charge separation in the filament tip [Raizer 1991, Kulikovsky 1997, Kulikovsky 1998].

The increase in current at the beginning of Region 3 marks the onset of secondary mode. One, or sometimes two, of the primary phase filaments emerges from the expanding bush of primary mode filaments and branches into other filaments, which all propagate simultaneously and develop into a tree-like pattern (figure 2.3c). 

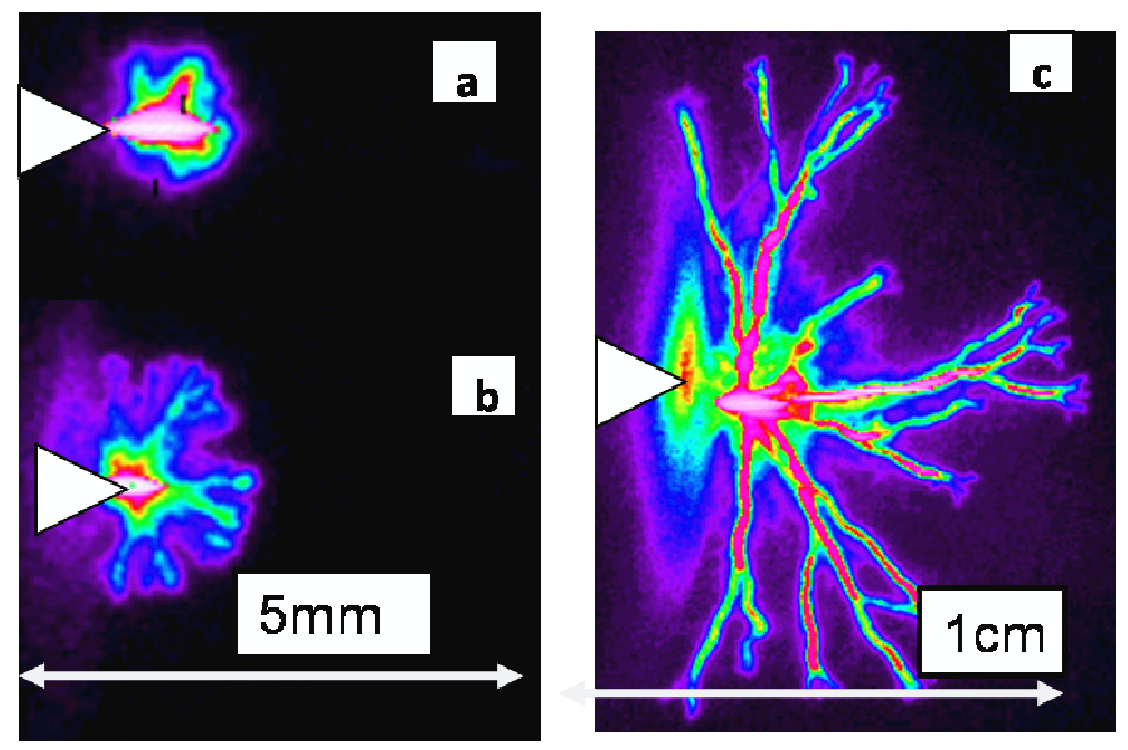

Figure 2.3 The transition between the primary modes (a) to the secondary mode (c) captured in time resolved images (2ns). (From Ceccato 2009b)

In low conductivity water some filaments which have ceased growing or emitting light will subsequently re-illuminate and continue to grow one filament at a time. This is in Region 4 in Figure 2.1. It is indicative of charge deposition and electric field separation at the plasma-liquid interface inducing dielectric-barrier-discharge-like behaviour.

In both the primary and secondary modes shadowgraph indicates the presence of shock waves at the tips of the filaments indicating that the growth of the filaments is stepwise rather than continuous.

The length of propagation of the filaments into the electrode gap depends on the applied voltage duration. If the filament reaches to the other electrode an arc is created. If the filaments fail to reach the other electrode the gas channels left behind expand and fragment into a string of micro bubbles.

The negatively-biased pin electrode discharges are also filamentary but the propagation mechanism is clearly different since the electrons come to the interface from the liquid in the positive case and from the vapour with negative polarity. The light emission, which is significantly less than that in positive polarity, starts almost immediately after the application of the high voltage and propagate more slowly than with positive polarity.

\subsection{Low voltage breakdown in saline}

The production of plasmas in saline solution at low voltages has been studied for some time by Stalder and co-workers [Stalder et al. 2001, Woloszko et al. 2002, Stalder et al 2005, Stalder and Woloszko 2007]. It was shown that the plasma production was associated the initial production of a vapour layer on the electrode surface. Recently this work has been extended to specific experimental measurements of vapour layer and computer simulation [Schaper et al. 2010a, Schaper et al. 2010b].

In Schaper et al.'s experiments, the plasma was created in the vicinity of a $0.5 \mathrm{~mm}$ diameter tungsten tip electrode insulated so that only the last $0.5 \mathrm{~mm}$ is immersed in $0.9 \% \mathrm{NaCl}$ solution $(\mathrm{w} / \mathrm{w})$. The return electrode is a grounded plate in the liquid. A 20 ns risetime high- 
voltage switch supplies a single DC voltage pulse to the powered electrode with a duration of up to $10 \mathrm{~ms}$.

The time dependence of the plasma produced light emission was monitored using a fast photomultiplier tube and the time integrated spectra over the period of the pulse were measured using an imaging spectrograph. An ICCD was used to obtain time resolved images of the plasma emission and shadowgraphs of the electrode tip region. Finite element multiphysics software, coupling thermal and electrical effects, is employed to model the vapour layer formation [Schaper et al. 2010a].

The typical electrical behaviour of the system when a $9 \mathrm{~ms},-225 \mathrm{~V}$ applied voltage pulse is applied to the tip electrode shown in Figure 2.4. The first 0.7 to $1.1 \mathrm{~ms}$ of the electrical behaviour of the system is very reproducible from pulse to pulse and is seen to be associated with the growth of a vapour layer over the electrode. The vapour layer production process is reproducible and can be simulated in the finite element multiphysics based simulation of the vapour layer formation. [Schaper et al. 2010a].

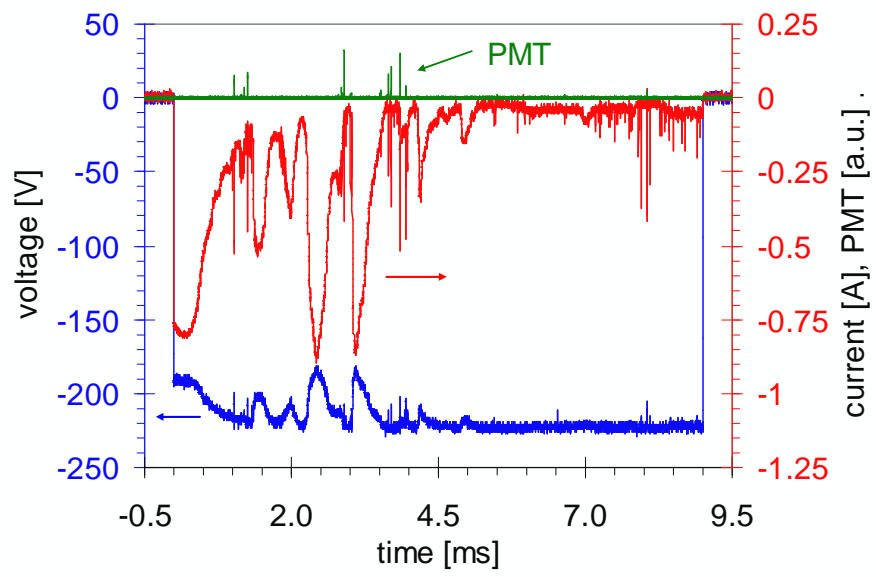

Figure 2.4, The measured current and voltage time dependence of the system during a $9 \mathrm{~ms},-225$ $\mathrm{V}$ pulse with liquid at room temperature $\left(\sim 20^{\circ} \mathrm{C}\right)$. Also shown is the response of a fast photomultiplier tube (PMT) viewing the electrode tip region [from Schaper et al. 2010b].

For positive polarity the final layer depth and the depth at full coverage are similar to those with negative polarity pulses, the time scales to reach those stages are about $30 \%$ longer.

For negative polarity discharges the exact time of the first light emission varies from pulse to pulse but $95 \%$ of the voltage pulses produce first light emission - originating from plasma production in the vapour layer-between 0.7 and $1.1 \mathrm{~ms}$ after their start. By this time the vapour layer has grown to a thickness of about $250 \mu \mathrm{m}$ over the electrode surface. This implies electric fields of $\sim 10^{6} \mathrm{Vm}^{-1}$ in the vapour layer, close to the values of $2.5 \times 10^{6}$ to $7.5 \times 10^{6} \mathrm{Vm}^{-1}$ predicted by the simulations of vapour growth [Schaper et al. 2010a].

The images in Figure 2.5 show that the intensity and volume of the plasmas produced vary greatly and are unpredictable. However they can be broadly classified as follows: Short lived $(\sim$ few $\mu \mathrm{s})$, low intensity plasmas, connected to the electrode surface and occurring through out the voltage pulse (Figures $2.5 \mathrm{a}-\mathrm{c}$ ), Long lived, high intensity plasmas, persisting for up to $500 \mu \mathrm{s}$ and spreading from the surface more extensively into the vapour layer (figure $7 \mathrm{~d}$ ). The first plasmas can be either short or long lived but have a maximum duration of about $100 \mu \mathrm{s}$. The 
location of the discharges is also unpredictable however, from the statistical spatial distribution of first discharges, it is clear that they are predominantly produced at the rim of the electrode where the electric field strength would be at a maximum.

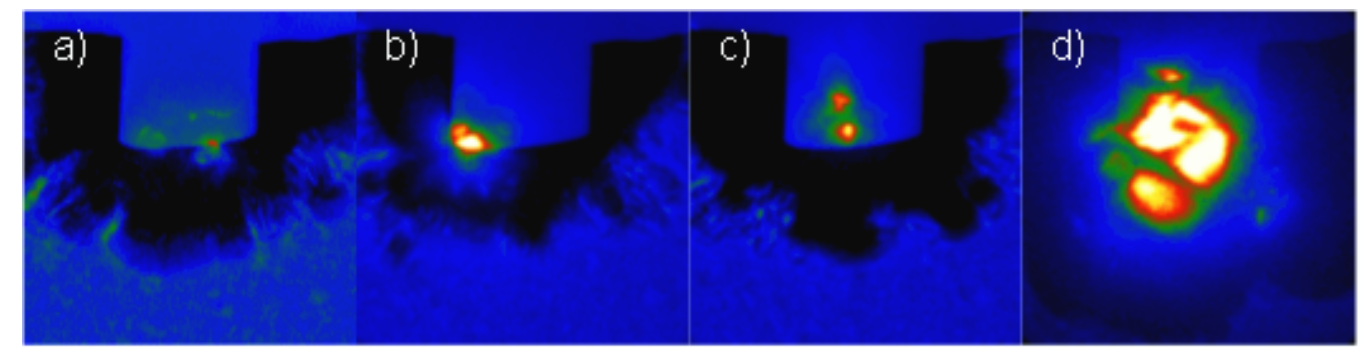

Figure 2.5. ICCD images of typical discharges. The dark areas are vapour. For $\mathrm{a}, \mathrm{b}$ and $\mathrm{c}$ the ICCD gate width was $100 \mu$ s, delayed $1 \mathrm{~ms}$ from the pulse initiation. For $\mathrm{d}$ the ICCD gate width was $10 \mu \mathrm{s}$, delayed $1.1 \mathrm{~ms}$ from the pulse initiation [from Schaper et al. 2010b].

For positive polarity the final layer depth and the depth at full coverage are similar to those with negative polarity pulses, the time scales to reach those stages are about $30 \%$ longer and higher voltages are required to initiate the discharges,

In summary, these measurements confirmed that plasma production occurred in vapour layers formed on the electrode and this happens after the vapour layer has completely covered the exposed electrode tip. The vapour layer is approximately $0.3 \mathrm{~mm}$ thick when the first plasma occurs. The high electric fields in the vapour layer, approach $10^{7} \mathrm{Vm}^{-1}$, the presence of a sodium and chlorine on the electrode surface and sodium in the vapour layer. There are generally multiple plasmas of different character in each pulse. They can be broadly classified as short (few $\mu$ s) or long (up to $500 \mu \mathrm{s}$ ) lived. The reproducible vapour layer formation make these systems particularly conducive to fundamental studies of the physics and chemistry of plasmas in liquids.

\section{Chemistry}

As noted above, electrical discharges in liquids and vapours above them frequently produce plasmas that are highly non-equilibrated in the sense that the electron temperature is significantly higher than the ion and neutral molecule temperatures. This condition leads to numerous electron-collision-dominated reactions that can fragment molecules into neutral and ionic products. Subsequent ion-molecule reactions subsequently produce additional chemical species not formed in the initial collision. Since the neutral vapour densities are usually quite large at typical atmospheric pressures and temperatures, the chemical kinetics drives the production of new species on rapid time scales.

Aqueous solutions are dominated by water, with minor concentrations of added solutesfrequently easily dissolved salts-providing means by which the conductivity of the liquid can be adjusted. Electrical discharges dissipate heat through Joule heating of these conductive solutions, and, if the local heating rate is sufficiently large compared to the rate at which the energy is dissipated through heat conduction or convective processes the liquid can vaporize. Due to water's large dipole moment the salts are strongly bound to the water in the liquid phase and do not volatilize easily. So the vapour is dominated by water molecules in the form of steam. Energetic electrons in non-equilibrium plasmas formed in water vapour produce a number of primary species through reactions such as:

$$
\mathrm{e}+\mathrm{H}_{2} \mathrm{O} \rightarrow \mathrm{H}+\mathrm{OH}+\mathrm{e},
$$




$$
\begin{aligned}
& \mathrm{e}+\mathrm{H}_{2} \mathrm{O} \rightarrow 2 \mathrm{H}+\mathrm{O}+\mathrm{e} \\
& \mathrm{e}+\mathrm{H}_{2} \mathrm{O} \rightarrow \mathrm{H}_{2} \mathrm{O}^{+}+2 \mathrm{e}
\end{aligned}
$$

Hydrogen atoms $[\mathrm{H}]$ and hydroxyl radicals $[\mathrm{OH}]$ are extremely reactive chemical species and can interact strongly with nearby materials, especially organic molecules containing significant hydrogen-terminated groups. The primary species in the vapour phase can also subsequently react with one another to produce a number of secondary species, usually influenced strongly by the presence of third bodies $[\mathrm{M}]$ to conserve energy and momentum in the association reactions:

$$
\begin{aligned}
& \mathrm{OH}+\mathrm{OH}+\mathrm{M} \rightarrow \mathrm{H}_{2} \mathrm{O}_{2}+\mathrm{M} \quad[\mathrm{M}=\text { third body }] \\
& \mathrm{O}+\mathrm{O}+\mathrm{M} \rightarrow \mathrm{O}_{2}+\mathrm{M} \\
& \mathrm{O}+\mathrm{O}_{2}+\mathrm{M} \rightarrow \mathrm{O}_{3}+\mathrm{M}
\end{aligned}
$$

Here, the third body $\mathrm{M}$ is typically $\mathrm{H}_{2} \mathrm{O}$, because water comprises the bulk of the vapour in which the plasma is formed. Thus, more stable but still chemically active species such as hydrogen peroxide $\left[\mathrm{H}_{2} \mathrm{O}_{2}\right]$ and oxygen $\left[\mathrm{O}_{2}\right]$ and ozone $\left[\mathrm{O}_{3}\right]$ are formed. It should also be noted that long lived metastable species such as singlet oxygen $\left[\mathrm{O}_{2}\left({ }^{1} \Delta_{\mathrm{g}}\right)\right]$, and superoxide ions $\left[\mathrm{O}_{2}{ }^{-}\right]$, and protonated water cluster ions $\mathrm{H}^{+} \cdot \mathrm{H}_{2} \mathrm{O}$ can also be produced in the vapour phase. Chemical kinetics software can be used to follow the evolution of all the relevant species once the rate constants and initial species concentrations are specified. [e.g. Gao et al. 2001, Gao et al. 2003a, Gao et al. 2003b, Gao et al. 2004, Stalder et al. 2005, Gao et al. 2006, Wang et al. 2008, Wang 2009]

Many of the species produced by the reactions outlined above are water soluble and thus can react with solutes in the liquid phase. Hydrogen peroxide and ozone are notable in this regard. In fact these are the species most sought after for electrical discharges in liquids used for pollution remediation.

The energetic free electrons in the vapour phase continuously react with the vapour species and lose energy. Their ultimate fate depends on whether they react to form negative ions, such as the superoxide ion $\mathrm{O}_{2}^{-}$, or whether they enter the liquid phase and become bound to water molecules to form so-called aqueous electrons, $\mathrm{e}_{\mathrm{aq}}$. Aqueous electrons can also react with solute particles. Studies relating to the radiation chemistry induced by high-energy electron beams interacting with liquid-phase and vapour-phase water provide significant data on the chemistry of aqueous electrons [Jonah 1995, Pimblott and LaVerne 1998]. There have been some studies of the chemistry of aqueous electrons and hydroxyl radicals reacting with biological molecules, including DNA [e.g. LaVerne and Pimblott 1993 and Falcone et al. 2005]. Although these studies usually involve the impact of very high energy electrons $(>1 \mathrm{keV})$ on liquid water, there is significant energy loss through linear energy transfer (LET) mechanisms so that the electrons eventually degrade to energies that produce low-energy electrons, aqueous electrons and radicals relevant to the low-temperature nonequilibrium plasmas of interest in this review.

Chemically-active species produced in the vapour phase plasma can also diffuse to the vapour-liquid interface and enter the liquid; conversely species in the liquid phase can diffuse to the liquid-vapour interface and enter the vapour. The net transport of species across the interface is called the uptake coefficient. Studies on the atmospheric chemistry of radicals and liquid droplets provide information on many of these processes for species related to water. For example, the uptake coefficient for hydroxyl radicals $[\mathrm{OH}]$ entering liquid water has been measured to be greater than $2 \times 10^{-3}$. [Takami et al. 1998]

Some relatively high-energy $(\sim 10 \mathrm{eV})$ electrons in the high energy tail of the electron energy distribution of the low-temperature nonequilibrium plasmas can impinge on the liquid and induce chemistry directly at the interface. These can leave the vapour phase discharge and deposit their energy within microns of the water interface. The ionization threshold in water is 
$13 \mathrm{eV}$ and the excitation threshold is $\sim 7.4 \mathrm{eV}$. Since the $\mathrm{O}-\mathrm{H}$ bond energy is $\sim 5 \mathrm{eV}$ water molecules will break up to give a series of reactive radicals $\left(\mathrm{OH}, \mathrm{H}, \mathrm{HO}_{2}\right)$ and possibly a small yield of positive and negative ions $\left(\mathrm{H}_{3} \mathrm{O}^{+}, \mathrm{OH}^{-}\right)$. The electrons will rapidly become thermalised and hydrated on sub-nanosecond timescales to form aqueous electrons $\mathrm{e}_{\text {aq }}$. Typically the radical and aqueous electron lifetimes will be of the order of microseconds.

Experimental studies of the products and rates of bimolecular and termolecular chemical reactions of plasma-produced species of the sort described above are relatively tractable using conventional chemical techniques, including chromatography, optical absorption spectroscopy and mass spectroscopy. Studies of the interactions of plasma-produced species with solid targets are much less amenable to basic chemical methods. In this case, modelling can be particularly helpful to provide insight and sometime. For example, it is well known from organic chemistry that hydrogen atoms and hydroxyl radicals are particularly reactive towards alkanes. Attempts to understand how plasmas interact with collagen triple helix molecules in moist environments borrow ideas from these types of reactions, plus hydrolysis, to propose a chemical model that might explain the observed efficient ablation in plasma-based electrosurgery [Stalder et al. 2005]

\subsection{Spectroscopy}

Plasmas produced in liquids usually produce some observable optical emissions. In the case of high energy discharges in highly purified water the radiation can be quite intense and significant in the UV wavelength range [Robinson et al. 1973]. In low-voltage discharges the radiation is also frequently clearly visible, but is usually dominated by the salt cations used to increase the conductivity of the water. For example, electrosurgical plasmas produced by electrical discharges in $\mathrm{NaCl}$-based saline solutions produce sodium D-line emission at $589 \mathrm{~nm}$, which gives rise to their characteristic orange glow [Stalder et al. 2001, Woloszko et al. 2002]. These types of lowvoltage discharges also produce UV and visible emissions associated with excited state $\mathrm{OH}^{*}$ and $\mathrm{H}^{*}$ species, thus indicating that even low-energy discharges can produce electron energies sufficient to fragment water molecules into excited products. Recently Bruggeman and colleagues [Bruggeman, et al. 2010] have pointed out that $\mathrm{OH}^{*}$ may also be produced by dissociative recombination of $\mathrm{H}_{2} \mathrm{O}^{+}$ions and electrons. This process is likely to occur at low pressures and may also occur at atmospheric pressure. However, clustering reactions of $\mathrm{H}_{2} \mathrm{O}^{+}$ with water molecules at atmospheric pressure are rapid, so this species is usually not the dominant positive ion in these discharges. The reactions are numerous, and many of the relevant ones have been tabulated by Bychkov and Yurovskii in their studies of electron-beam-induced ionization in water vapour [Bychkov and Yurovskii 1993]. .A very nice optical emission study of DC-excited discharges in low conductivity water was recently reported [Bruggeman et al. 2009b] Plasmas produced by contact glow discharge electrolysis also produce spectra characteristic of the salts in the liquid [Kobayashi et al. 2000].

\section{Applications in Nanoscience}

Nanoparticle growth in plasmas in liquids has been explored by a number of groups and here we have selected a few examples to illustrate the type of nanoparticles that can be produced and some of the techniques that have been used.

Jwo et al. 2005 prepared $\mathrm{TiO}_{2}$ nanoparticles using a pulsed arc system in deionized water maintained at a reduced pressure of 50 torr. The voltage required to produce an arc under these conditions was only 100 volts, with positive polarity, and a maximum current of 2.5 A was developed. The voltage was pulsed on for $10 \mu$ s and pulsed off for $30 \mu$ s, thus using a $25 \%$ duty cycle, for a working time of 10 minutes. Particle diameters ranging from about 5-15 nm were reported. 
Sergiienko et al. 2006 and Shibata et al. 2007 have reported on the use of an electrical discharge in liquid ethanol to synthesis of iron and cobalt carbide-filled carbon nanocapsules. They used a low current plasma discharge, generated between an immersed $\mathrm{Fe}$ (or $\mathrm{Co}$ ) anode and cathode. The cathode is fixed to the top of an ultrasonic horn allowing bubbles to be introduced between the electrodes. A DC voltage difference of $55 \mathrm{~V}$ between the anode and cathode is sufficient to create the plasma. A carbonaceous powder is formed in the liquid ethanol which after treatment if found to contain carbon nanocapsules with spherical, crystalline carbide (orthorhombic $\mathrm{Fe} 3 \mathrm{C}$ and monoclinic $\chi$-Fe2.5C structures) cores about $5 \mathrm{~nm}$ in diameter and covered with graphite layers. Whole samples showed a ferromagnetic behaviour, attaining saturation at fields of $\pm 1200 \mathrm{kAm}^{-1}$.

Toriyabe et al. 2007 produced spherical metallic nanoparticles, which they refer to as "nanoballs," in a plasma electrolysis cell. Their composition include $\mathrm{Ni}, \mathrm{Ti}, \mathrm{Ag}$, and $\mathrm{Au}$, and they have a rather broad size distribution with a mean size of between about 100-400 nm, depending on the cell voltage. The trend in the data suggests that they might achieve sub-100-nm mean diameters if the cell voltage exceeded 200 volts. They report the typical I-V characteristic of these types of discharges, and show evidence of a glow discharge formed in the thin vapor layer covering the biased electrode.

Gold nanoparticles around 10-50 $\mathrm{nm}$ in size have been synthesized [Hieda et al. 2008 and Takai 2008] using a pulsed DC discharge. The typical preparation conditions used a chloraunic acid $\left(\mathrm{HAuCl}_{4}\right)$ stabilized by the addition of sodium dodecyl sulfonate to prevent particle agglomeration. The applied voltages were between 1.6 and $3.2 \mathrm{kV}$, and pulses at $15 \mathrm{kHz}, 2 \mu \mathrm{s}$ pulse widths were used. They believe hydrogen atoms are essential as reducing agents for the particle growth to proceed. Hydrogen peroxide was also detected. Although the starting solution was highly acidic to begin with $(\mathrm{pH} \sim 3.1)$, the discharge reduced the $\mathrm{pH}$ even further to about 2.6. The gold nanoparticles had average diameters of $10.5 \pm 3.6 \mathrm{~nm}$. In addition it was possible to synthesis of topological ( e.g. trigonal, pentagonal, and hexagonal) gold nanoparticles.

Cabanillas et al. 2010 were able to fabricate spherical iron particles in liquid nitrogen using what they call a spark erosion process. They employed a commercial electric discharge machining (EDM) system. Arc currents of 9.5 to 25 amps were used. They used a pulsed voltage source, with an on time of $3000 \mu \mathrm{s}$ and an off time of $340 \mu \mathrm{s}$. The particle size distribution was rather broad, ranging from about 5 microns to greater than 1 micron in diameter.

Burakov et al. 2009 made copper-based nanoparticles in either ethanol or distilled water by applying $3.5 \mathrm{kV}$ pulses at $100 \mathrm{~Hz}$. They claim two distinct modes of operation; either an arc discharge, or a pulsed spark discharge, a local thermodynamic equilibrium (LTE) conditions were achieved under either mode. The pulsed arc discharge developed currents as large as 9 amps with a rather long pulsed duration of $4 \mathrm{~ms}$. The pulsed spark discharge developed a current up to 60 amps but for a much shorter duration of $30 \mu \mathrm{s}$. They performed optical spectroscopic measurements and focused attention on the broadening of the $\mathrm{H}_{\alpha}$ emission line. The electron temperatures thus derived by them ranged from about 1.0 to $1.4 \mathrm{eV}$, depending on discharge model and liquid. The electron density was about $3-4 \times 10^{16} \mathrm{~cm}^{-3}$ in the arc discharge, but ranged from about 30-60 $\times 10^{16} \mathrm{~cm}^{-3}$ in the pulsed spark discharge, depending on whether water or ethanol was used at the dielectric liquid.

Some of the other nanoscience related applications of plasmas in liquids include the deposition of graphite films and surface modification. Paulmier et al. 2007a,b reports on the deposition of nanocrystalline graphite films in $96 \%$ ethanol with $4 \%$ phosphate buffer and $0.2 \mathrm{M}$ $\mathrm{KCl}$ added to provide conductivity to the solution. They reported that the conductivity of this solution was $16.7 \mathrm{mS} / \mathrm{m}$. A ramped negative DC voltage (cathodic) was applied to the central electrode, composed of either $\mathrm{Cu}, \mathrm{Al}$ or Ti, starting at 0 and ending at -1000 volts after typically 400 seconds. The I-V curves showed characteristics typical of these kinds of discharges, with impedance starting to increase at a voltage of about -200 volts, indicative of vapour layer formation. Plasma discharges began to appear at about -400 volts. A carbon film was deposited, 
and Raman analysis confirmed both diamond-like and graphite-like characteristics of the disordered film. Interestingly, the optical emission spectrum at relatively high voltages, 700 and 1000 volts, showed a rather broad continuum ranging from about $400 \mathrm{~nm}$ to $900 \mathrm{~nm}$ along with the expected peaks characteristic of the Titanium electrode, and water dissociation products.

Nomura et al. 2006 have also demonstrated the synthesis of carbon-related materials with a microwave-generated plasma in a hydrocarbon liquid but under vacuum. The vacuum prevents the oxidation of products such as graphite, silicon carbide, diamond-like carbon, and carbon nanotubes. The most attractive feature of this process is that the liquid phase plays an important role as a plasma reactor. However, this method is limited to nonpolar solvents such as hydrocarbons, because polar solvents adsorb microwaves and prevent plasma formation.

Oxidation, nitriding, and carburizing are also of nanoscience interest. These processes been investigated mainly with the gas-phase plasma however Takai 2008 also reports that plasma formation can also be used to enhance electroplating, in this case pulsed $(60 \mathrm{~Hz})$ electroplating with $2 \mathrm{~g} / \mathrm{L} \mathrm{NaOH}$ in deionized water as the electrolyte. The applied voltage was made high enough $(175 \mathrm{~V})$ to have short-lived and randomly moving microarcs develop on the surface of the aluminium anode. The growth rates of aluminium and titanium oxide films increased with discharge current densities. A high growth rate of $1.7 \mu \mathrm{m} / \mathrm{min}$ was obtained for both aluminium and titanium oxide. The aluminium oxide film consisted of two layers, as revealed by SEM observation of the cross-section of an aluminium substrate after modification. The external layer had low strength and high porosity, and could be removed easily. The internal layer was hard and adhered well to the substrate, believed to be because of locally developed transient high temperature melted the growing oxide layer on the substrate and improved the adherence.

\section{Conclusions.}

Plasmas or discharges produced in liquid have been studied for some time. As the understanding of their underlying physics and chemistry has progressed their exploitation into areas such as biomedicine and nanoscience has created much interest and excitement. In much of the fundamental plasma research the liquid has been water. These studies show that in water the discharges or plasmas are formed in water vapour created by Joule heating either as channels in the liquid or as layers on the electrodes.

The plasmas created are often highly non-equilibrated i.e. the electron temperature is significantly higher than the ion and neutral atom and molecule temperatures. The result is that numerous electron-collision-dominated reactions occur in such plasmas producing dissociation of molecules into reactive and charged species. In the highly collisional atmospheric pressure environment chemical kinetics produces further species on rapid time scales. In water vapour this produces species $\mathrm{OH}, \mathrm{H}, \mathrm{HO}_{2}$ and $\mathrm{H}_{2} \mathrm{O}_{2}$ and smaller yields of positive and negative ions and their hydrated clusters.

Plasmas in liquids are already being used in nanoscience for nanoparticle, film growth and surface functionalisation. The pressing issue in optimizing and extending the use of plasmas in liquids is to understand the plasma-induced physical and chemical phenomena exhibited in current, well defined applications. This understanding can then identify and inform the implementation of other potential applications. The complexity of these environments is challenging but the synergistic use of the multi-physics and plasma chemistry computer-based simulations and advanced imaging and spectroscopic tools, as described above, is already providing new insights. Important to interpreting the results of such measurements and as additional input to the simulations will be learning from and using the large knowledge and data base generated for many years by the radiation chemistry community. In addition the full potential from using other liquids, liquid mixtures and dissolved precursors will allow the creation of a plethora of reactive species. This will lead to an enhanced ability 
to predetermine the liquid-plasma device combinations best tuned for specific applications, in a similar manner to the approaches that have been successful in the microelectronics industry. It will create many more opportunities to exploit plasmas in liquids across the whole technological landscape, including nanoscience. The immediate challenge now is to get plasma and materials scientists working closely together to understand the key processes and phenomena.

\section{References.}

An W, Baumung K and Bluhm H 2007 J. Appl. Phys. 101053302

Baba K, Okada T, Kaneko T, Hatakeyama R 2006 Jap. J. Appl. Phys. 45 8286-8289

Beroual A, Marteau C and Tobazeon R 1988 IEEE Trans. on Elect. Insulat. 23, 955-959

Beroual A 1993 J. Appl. Phys 73 4528-4533

Boguslavsky L Z, Kha-Ůatsky S A and Shcherbak A N 2001 Technical Phys. 46 174-178

Bruggeman P and Leys C 2009a J. Phys. D: Appl. Phys. 42053001

Bruggeman P, Schram D C, González M Á, Rego R, Kong M G and Leys C 2009b Plasma

Sources Sci. Technol. 18025017

Bruggeman P, Verreycken T, González M Á, Walsh J L, Kong M G, Leys C and Schram D C 2010 J. Phys. D: Appl. Phys. 43124005

Burakov V, Tarasenko N, Nevar A A and Nedelko V I 2009 Proc. 29th Int. Conf. Phys. Ioniz.

Gases (Cancun Mexico)

Bychkov V L and Yurovskii V A 1993 Institute of High Temperatures, Russian Academy of Sciences. Translated from Teplofizika Vysokikh Temperatur 31 8-17Cabanillas E D, Granovsky M S and Ratner M J 2010 Acta Microscopica 19 190-195Ceccato P 2009a "Filamentary plasma discharge inside water: initiation and propagation in a dense medium" PhD Thesis Ecole Polytechnique.

Ceccato P, Guaitella O, Schaper L, Graham W and Rousseau A 2009b IEEE Pulsed Power Conf. Proc. 2 863-868

Ceccato P, Guaitella O, Rabec Le Gloahec M, Rousseau A 2010 J. Phys. D: Appl. Phys. 43

175202

Chadband W G 1988 IEEE Trans on Elect. Insulat.l 23 697-706

Chang F-C, Richmonds C and Sankaran R M 2010 J. Vac. Sci. Technol. A 28 L5-L8

Chiang W-H, Richmonds C and Sankaran R M 2010 Plasma Sources Sci. Technol. 19034011

De Baerdemaeker F, Šimek M, Schmidt J and Leys C 2007 Plasma Sources Sci. Technol. 16 341354

Devins J C and Rzad S J 1982 IEEE Transactions on Elect. Insulat. 17 512-516

Falcone J M, Becker D, Sevilla M D and Swarts S G 2005 Rad. Phys. Chem. 72 257-264

Flannigan D J and Suslick K S 2005 Nature 434 52-55

Fofana I and Beroual A 1998 Jap. J. Appl. Phys. 37 2540-2547

Gao J, Hu Z, Wang X, Hou J, Lu X and Kang J 2001 Thin Solid Films 390 154-158

Gao J, Liu Y, Yang W, Pu L, Yu J and Lu Q 2003a Plasma Sources Sci. Technol. 12 533-538

Gao J, Wang X, Hu Z, Deng H, Hou J, Lu X and Kang J 2003b Water Research 37 267-272

Gao J, Yu J, Lu Q, Yang W, Li Y and Pu L 2004 Pakistan J. Biolog. Sci. 7 1715-1720

Gao J, Yu J, Li Y, He X, Bo L, Pu L, Yang W, Lu Q and Yang Z 2006 J. Hazard. Mat. B137 431-436

Hieda J, Saito N and Takai O 2008 J. Vac. Sci. Technol. A 26 854-856

Janca J, Kuzmin S, Maximov A, Totova J and Czernichowski A 1999 Plasma Chemistry Plasma Processing 19 53-67 
Jonah C D 1995 Rad. Res. 144 141-147

Jones H M and Kunhardt E E 1994 IEEE Trans. on Dielect. and Elect. Insulat. 1 1016-1025

Jwo C-S, Tien D-C, Teng T-P, Chang H, Tsung T-T, Liao C-Y and Lin C-H 2005 Rev. Adv.

Mater. Sci. 10 283-288

Kirkpatrick M J and Locke B R 2006 Ind. Eng. Chem. Res. 45 2138-2142

Kitano K, Aoki H and Hamaguchi S 2006 Jap. J. Appl. Phys. 45 8294-8297

Kobayashi K, Tomita Y and Sanmyo M 2000 J. Phys. Chem. B 104 6318-6326

Kolb J F, Joshi R P, Xiao S and Schoenbach K H 2008 J. Phys. D: Appl. Phys. 41234007

Kulikovsky A A 1997 J. Phys. D: Appl. Phys. 30 441-450

Kulikovsky A A 1998 Phys. Rev. E 57 7066-7074

LaVerne J A and Pimblott S M 1993 Rad. Res. 135 16-23

Lesaint O and Gournay P 1994 J. Phys. D: Appl. Phys. 27 2111-2116

Liu Y and Jiang X 2008 Plasma Chem. Plasma Proc. 28 15-24

Locke B R, Sato M, Sunka P, Hoffmann M R, and Chang J S 2006 Ind. Eng. Chem. Res. 45 882905

Lukeš P, Appleton A T, Locke B R 2004 IEEE Trans. on Industry Applications 40 60-67

Malik M A, Ghaffar A and Malik, S A 2001 Plasma Sources Sci. Technol. 10, 82-91

Martin T H, Williams M and Kristiansen M 1996 Advances in Pulsed Power Technology (Berlin:

Springer)

Massala G and Lesaint O 1998 IEEE Trans. Dielect. and Elect. Insulat. 5 371-381

Messing M E, Dick K A, Wallenberg L R and Deppert K 2009 Gold Bulletin 42 20-26

Mizuno T, Akimoto T, Azumi K, Ohmori T, Aoki Y and Takahashi A 2005 Jap. J. Appl. Phys. 44

396-401

Nahen K and Vogel A 1996 IEEE Journal of Selected Topics in Quantum Electronics 2 861-871

Nomura S. Toyata H, Mukasa S, Yamashita H, Maehara T and Kuramoto M 2006 Appl. Phys.

Lett. 88211503

Paulmier T, Bell J M and Fredricks P M 2007a Surf. Coat. Technol. 201 8771-8781

Paulmier T, Bell J M and Fredricks P M 2007b Thin Solid Films 515 2926-2934

Pimblott S M and LaVerne J A 1998 Rad. Res. 150 159-169

Raizer Y P 1991 Gas discharge Physics ( Berlin:Springer)

Richmonds C and Sankaran R M 2008 Appl. Phys. Lett. 93131501

Robinson J W, Ham M and Balaster A N 1973 J. Appl. Phys. 44 72-75

Sakiyama Y, Tomai T, Miyano M and Graves D B 2009 Appl. Phys. Lett. 94 161501-161503

Schaper L, Graham W G and Stalder K R 2010a Submitted to PSST

Schaper L, Stalder K R and Graham W G 2010b Submitted to PSST

Sengupta S K, Singh R and Srivastava A K 1998 J. Electrochem. Soc. 145 2209-2213

Sengupta S K, Srivastava A K and Singh R 1997 J. Electroanalytical Chemistry 427 23-27

Sergiienko R, Shibata E, Akase Z, Suwa H, Nakamura T and Shindo D 2006 Mater Chem Phys

98 34-38

Shibata E, Zentaro A, Shindo D, Nakamura T and Qin G 2007 Acta Materialia 55, 3671-3680

Shirai N, Nakazawa M, Ibuka S, Ihsii S 2009 Jap. J. Appl. Phys. 48036002

Skibenko E I, Yuferov V B, Buravilov I V and Ponomarev A N 2006 Technical Phys. 51 1240-

1242

Stalder K R, Woloszko J, Brown I G, and Smith C D 2001 Appl. Phys. Lett. 79 4503-4505

Stalder K R, McMillen D F and Woloszko J 2005 J. Phys. D: Appl. Phys. 38 1728-1738

Stalder K R and Woloszko J 2007 Contrib. to Plasma Physics 47 64-71

Starikovskiy A Y, Yang Y, Cho Y.I and Fridman A 2010 Proc. $20^{\text {th }}$ ESCAMPIG (Novi

Sad, Serbia)Sugama C, Tochikubo F and Uchida S 2006 Jap. J. Appl. Phys. 45 8858-8863

Sunka P, Babický V, Člupek M, Fuciman M, Lukeš P, Šimek M, Beneš J, Locke B, Majcherová

Z 2004 Acta Physica Slovaca 54 135-145

Takai O 2008 Pure Appl. Chem. 80 2003-2011 
Takami A, Kato S, Shimono A and Koda S 1998 Chem. Phys. 231 215-227

Toriyabe Y, Watanabe S, Yatsu S, Shibayama T and Mizuno T, 2007 Appl. Phys. Lett. 91041501

Touya T, Reess T, Pecastaing L, Gibert A and Domens P 2006 J. Phys. D: Appl. Phys. 395236

Vasily Y and Ushakov et al., 2007 Impulse Breakdown of Liquids, Power Systems, (Berlin, Heidelberg: Springer)

Vogel A, Nahen K, Theisen D and Noack J 1996 IEEE Journal of Selected Topics in Quantum Electronics 2 847-860

Wang L, Jiang X and Liu Y 2008 J. Hazard. Mat. 154 1106-1114

Wang L 2009 J. Hazard. Mat. 171 577-581

Woloszko J, Stalder K R and Brown I G 2002 IEEE Trans. Plasma Science 30 1376-1383

Yan Z-c, Chen L, Wang H-1 2006 The Chinese J. Process Eng. 6 396-401

Yan Z, Chen L and Wang H 2008 J. Phys. D: Appl. Phys. 41155205

Yerokhin A L, Nie X, Leyland Y, Matthews A and Dowey S J 1999 Surf. Coatings Technol. 122 73-93 